\title{
Necessidades e dificuldades de tutores e facilitadores para implementar a políicica de educação permanente em saúde em um município de grande porte no estado do Paraná, Brasil ${ }^{*}$
}

Fernanda de Freitas Mendonça ${ }^{1}$

Elisabete de Fátima Polo de Almeida Nunes²

MENDONÇA, F.F.; NUNES, E.F.P.A. Needs and difficulties of tutors and facilitators in implementing a continuing health education policy in a large municipality in Paraná. Interface - Comunic., Saude, Educ., v.15, n.38, p.871-82, jul./set. 2011.

To strengthen continuing health education (CHE) policies, tutors and facilitators of CHE have been trained. This study was proposed in order to uncover their needs and difficulties during the process of implementing $\mathrm{CHE}$. This was a qualitative investigation conducted among nine tutors and ten facilitators of CHE in the municipality of Londrina, Paraná. The data-gathering instrument consisted of semi-structured interviews and the data were analyzed in accordance with the discourse analysis proposed by Martins and Bicudo. The results showed that institutionalization of $\mathrm{CHE}$ was highlighted among the needs, and persistence of hegemonic practices was a difficulty. Based on the results, CHE needs to be consolidated through practicing it in healthcare services, because only in this way will tutors, facilitators and other healthcare professionals be able to overcome the limitations that permeate the process of implementing CHE.

Keywords: Health policy. Continuing Health Education. Work processes in healthcare. Personnel management in healthcare.
Para o fortalecimento da política de Educação Permanente em Saúde (EPS), tutores e facilitadores de educação permanente em saúde foram formados. No intuito de desvendar suas necessidades e dificuldades durante o processo de implementação da EPS, foi desenvolvida uma pesquisa qualitativa com nove tutores e dez facilitadores de EPS de Londrina, estado do Paraná. Como instrumento de coleta de dados foi realizada a entrevista semiestruturada, e os dados foram analisados conforme análise de discurso proposta por Martins e Bicudo. Entre as necessidades, destaca-se a institucionalização da EPS, e, como dificuldade, a persistência de práticas hegemônicas. Com base nos resultados é necessário consolidar a EPS por meio de sua prática nos serviços de saúde, pois só dessa maneira, tutores, facilitadores e demais profissionais de saúde terão capacidade de superar as limitações que permeiam o processo de implementação da EPS.

Palavras-chave: Política de saúde. Educação Permanente em Saúde. Processo de trabalho em saúde. Gestão de pessoal em saúde.

\footnotetext{
Elaborado com base em Mendonça (2007), pesquisa financiada pelo CNPQ e aprovada pelo Comitê de Ética da Universidade Estadual de Londrina.

${ }^{1}$ Curso de Enfermagem, Departamento de Enfermagem, Faculdade Integrado de Campo Mourão. Rodovia BR 158, KM 207. Campo Mourão, PR, Brasil. 87.300-970. fernandamendonca@ grupointegrado.br 2 Departamento de Saúde Coletiva, Universidade Estadual de Londrina.
} 


\section{Introdução}

O Ministério da Saúde (MS) instituiu a política nacional de Educação Permanente em Saúde (EPS), por meio da Portaria 198/GM, em 2004. Essa política surgiu com o propósito de transformar a assistência à saúde e a formação dos profissionais, buscando incorporar, às práticas de atenção e de ensino, a reflexão, a problematização, o trabalho em equipe e a integralidade, como também promover a articulação entre os órgãos de gestão, serviços de saúde, controle social e instituições de ensino (Brasil, 2004). Em 2007, houve reformulações na portaria que regulamentava esta política, sendo publicada, então, a portaria 1996/GM. Destaca-se que a nova portaria enfatiza as especificidades regionais como estratégia de identificar as distintas necessidades de formação e desenvolvimento do trabalho em saúde (Brasil, 2007).

Apesar de existir uma regulamentação garantindo a legalidade da política, havia muitas fragilidades entre os profissionais de saúde sobre o que era e como trabalhar com a EPS (Merhy, Feuerwerker, Ceccim, 2006). Portanto, para fortalecer essa política, o MS, em parceria com a Escola Nacional de Saúde Pública (ENSP), formou tutores e facilitadores de EPS em todo o país. O curso foi formatado em dois encontros presenciais e na modalidade de Educação a Distância (EAD), com duração de cinco meses. Em 2005, a proposta foi ampliada para municípios e regiões dispostos a adotar a EPS como estratégia de gestão da produção da saúde (Brasil, 2005a).

No Paraná, a equipe da autarquia do município de Londrina compreendeu o potencial da EPS como uma ferramenta capaz de promover mudanças no processo de trabalho em saúde. Dessa forma, para favorecer o desenvolvimento da EPS, houve a formação de nove tutores para apoiar a formação de cento e oitenta facilitadores.

Após a formação de tutores e facilitadores de EPS, nenhum processo de avaliação foi realizado, logo, não se conhecem quais as necessidades e dificuldades que esses sujeitos enfrentam para implementar a EPS nos dias atuais. Diante dessas lacunas de conhecimento e dos diversos obstáculos que permeiam o processo de implementação de EPS, sobretudo a reprodução das práticas hegemônicas, torna-se relevante investigar quais as necessidades e dificuldades vivenciadas por tutores e facilitadores de educação permanente em saúde no Município de Londrina, PR.

\section{Método}

Trata-se de um estudo descritivo-exploratório que utilizou a abordagem qualitativa. A pesquisa qualitativa trabalha com descrições dos fenômenos, sendo o significado a preocupação essencial desse tipo de abordagem (Triviños, 1987). Entende-se que o significado determina, ou seja, dá molde à forma como as pessoas pensam e agem; logo, é por meio da compreensão das significações que se conseguem desvelar as vivências e as representações que as pessoas têm a respeito de algo (Turato, 2005).

A pesquisa foi realizada no município de Londrina, PR, com nove tutores e dez facilitadores de EPS. Foram entrevistados todos os tutores do município, que fizeram o curso pelo MS, e os facilitadores que foram formados pelo município de Londrina.

Como o número de tutores era pequeno (nove), todos foram entrevistados. Por outro lado, o número de facilitadores (cento e cinquenta) foi determinado pela saturação das informações coletadas, ou seja, quando se perceberam repetições nas falas dos entrevistados, de modo que a inclusão de novos sujeitos não traria maior diversidade de informações.

A seleção dos facilitares de EPS ocorreu por amostragem intencional e orientada pelo critério de entrevistar pessoas de diferentes categorias profissionais, a fim de se desvelar o fenômeno sob os diferentes papéis que os profissionais ocupam em uma equipe. De acordo com Thiollent (2004), a amostragem intencional se justifica pela relevância que as pessoas selecionadas apresentam em relação a um determinado assunto.

Nesse estudo, utilizou-se como instrumento de coleta de dados a entrevista semiestruturada, a qual, além de valorizar a presença do pesquisador, oferece todas as perspectivas possíveis para que o 
informante alcance a liberdade e a espontaneidade necessárias. As entrevistas foram conduzidas por um roteiro contendo questões sobre a caracterização dos sujeitos do estudo e quatro questões referentes às percepções sobre: conceito de EPS, curso de facilitadores, necessidades e o papel do tutor e do facilitador de EPS. Contudo, neste estudo, o enfoque se limitou às questões que exploravam as necessidades e dificuldades pelos tutores e facilitadores de EPS. Salienta-se que este roteiro foi testado em entrevistas realizadas com um tutor e com um facilitador de outro município. O período de coleta de dados foi de dezembro de 2006 a janeiro de 2007.

As entrevistas foram gravadas e transcritas na íntegra. Foram retirados os vícios de linguagem e feita a correção ortográfica para proteção dos participantes da pesquisa.

Para a análise das entrevistas, foi utilizada a análise de discurso proposta por Martins e Bicudo (2005). Os participantes foram identificados por códigos a fim de se assegurar o sigilo de sua identidade. Para identificar os tutores, foi utilizada a letra T, e para identificar os facilitadores, a letra F. As entrevistas em cada grupo foram numeradas; logo, cada letra recebeu um número conforme a ordem da realização das entrevistas.

Os princípios éticos que nortearam esta pesquisa estão contemplados na Resolução 196/96, que regulamenta a pesquisa envolvendo seres humanos (Brasil, 1996). Esta pesquisa foi autorizada pela Autarquia Municipal de Saúde e aprovada pelo Comitê de Ética e Pesquisa UEL.

\section{Resultados e discussão}

\section{Caracterização dos participantes}

Dos 19 participantes do estudo, 16 eram do sexo feminino e a idade variou de 29 a 52 anos. Eles pertenciam a distintas categorias profissionais, destacando-se que todos os tutores possuíam formação universitária (enfermagem, medicina, odontologia e pedagogia), enquanto os facilitadores possuíam desde o Ensino Fundamental até o nível Superior (agente comunitário de saúde, auxiliar de enfermagem, enfermagem, medicina e odontologia).

Os entrevistados trabalhavam nos seguintes níveis de atenção à saúde: pronto-atendimento, urgência e emergência, especialidades, atenção básica, instituição de ensino, e profissionais que atuam no gerenciamento dos serviços de saúde em nível central.

\section{Categorias de análise}

Conforme mencionado anteriormente, o presente estudo aborda as categorias referentes às dificuldades e necessidades vivenciadas por tutores e facilitadores de EPS para implementar esta política durante o processo de trabalho em saúde.

\section{Dificuldades no processo de implementação da EPS}

Durante o processo de implementação da EPS, surgiram diversas dificuldades. Para eles, a assistência à saúde é fragmentada, as práticas são curativistas e centradas em procedimentos. O estudo de Peduzi (2007), realizado com gestores de serviços de saúde, revelou que a maioria dos estabelecimentos de saúde apresentam um trabalho individualizado por profissional.

\footnotetext{
"Nós ainda temos um sistema de saúde muito focado na pessoa do profissional médico, a população ainda vê dessa forma, os próprios profissionais também, muitos entendem dessa forma". (T6)
}

"Continua fragmentado, centrado lá no procedimento, no profissional". (F2) 
O estudo de Farah (2006), realizado num período em que a política de EPS ainda era incipiente, revela que os profissionais da equipe saúde da família já consideravam sua implementação como algo difícil por alterar uma lógica cristalizada.

A persistência das práticas hegemônicas e fragmentadas, ao mesmo tempo em que representa um desafio, também reforça a necessidade da implementação da política de EPS. Quando se fala em superar as práticas hegemônicas, é preciso ressaltar que não se trata de uma competição entre as práticas hegemônicas e as contra-hegemônicas, ou de definir em qual dessas práticas se encontra a verdade absoluta. Essa superação se faz necessária porque as práticas tradicionais não dão conta de responder aos desafios atuais, uma vez que há pouca abertura para o diálogo, para a escuta, para a integralidade e para a construção coletiva.

Além disso, a fragmentação da assistência, justificada muitas vezes pela complexidade dos problemas de saúde, tende a provocar desinteresse, alienação e a falta de responsabilidade nos profissionais de saúde (Brasil, 2005b; Campos, 1997). Outra consequência da fragmentação da assistência se expressa na falta de compreensão dos trabalhadores sobre a totalidade do trabalho (Ribeiro, Pires, Blank, 2004).

As práticas hegemônicas produzem alienação nos sujeitos e esta se manifesta pelo grau de afastamento do profissional de suas responsabilidades em defesa da vida e pelo modo como se estruturam as relações nos serviços de saúde (Campos, 1997). De acordo com Campos (1997), usuários e profissionais de saúde são reduzidos a objetos, redução que acontece quando há situações de desequilíbrio de poder, isto é, a detenção de poder provoca, no sujeito, o desejo de se impor, eliminando qualquer vestígio de piedade e de solidariedade. Essa tendência de tentar objetivar o trabalho em saúde, como se ele acontecesse independente do agente executor e do sujeito doente, faz com que os profissionais encarem o usuário como um objeto, e não uma pessoa. Assim, é necessário romper com essas representações e valorizar as subjetividades presentes no profissional e no usuário de saúde.

A falta de organização da demanda é apontada pelos sujeitos do estudo enquanto algo que sobrecarrega e limita a disponibilidade do facilitador em compartilhar os saberes e implementar a EPS com a equipe.

“ [...] a dificuldade é conciliar a possibilidade de você ter espaço de reflexão com a demanda do dia-a-dia! Se você não for uma pessoa que planeja, que seja firme em garantia de espaços de reflexão, você acaba se envolvendo na rotina do trabalho [...]". (T4)

Nesse discurso percebe-se quanto os participantes do estudo têm dificuldade de reconhecer os problemas do dia a dia enquanto fundamento para o exercício da EPS. É preciso salientar que a EPS se alimenta dos problemas e das necessidades presentes em um serviço de saúde. Como afirma Roschke (2006, p.35), a EPS "reconhece e opera com a complexidade, fragmentação, incerteza e o conflito inerente ao processo de trabalho nas instituições dos serviços." Campos (2007) sugere, como alternativa para atenuar a demanda de um serviço, o envolvimento dos usuários, das famílias e da comunidade com a produção de saúde. Salienta-se que a EPS se apoia, entre outras coisas, no protagonismo dos sujeitos, inclusive dos usuários.

Segundo alguns tutores, a limitação de governabilidade tem se constituído um fator que também traz dificuldades, por despertar a sensação de impotência e frustração.

"[...] eu tenho limite de atuação, passou daquele limite, minha governabilidade é nula, então [...] não consigo mais". (T1)

"[...] é um espaço de muito sofrimento para o trabalhador, de muita frustração porque é tão complexo que muitas vezes têm alguns fatores que você não consegue intervir".

É importante destacar que a limitação de governabilidade não é um problema em si; o que torna isso um problema é quando seus limites são reduzidos, tirando dos profissionais um poder, ou seja, uma autonomia que lhe era essencial para promover uma assistência à saúde de qualidade. 
Testa, citado por Giovanella (1989), ao falar sobre os resultados do exercício do poder, considera o poder cotidiano e o societal. O poder cotidiano se concretiza nas decisões do dia a dia sobre como e o que fazer. Por outro lado, o poder societal resulta da construção da sociedade; dessa forma, se processa a longo prazo. É importante enfatizar que o poder cotidiano está contido no poder societal; logo, há uma determinação do primeiro sobre o segundo. Nesse sentido, é preciso que se valorizem os resultados obtidos pelo poder cotidiano, ou seja, mesmo havendo limitações de atuação, o sujeito deve valorizar as ações que estão dentro de seu alcance.

Outra dificuldade relatada por tutores refere-se à falta de comprometimento e responsabilização dos profissionais com o serviço público.

Confirmando os resultados desta pesquisa, o estudo realizado por Cotta et al. (2006), com profissionais da atenção básica, revela que a insatisfação salarial é uma entre as razões que levam os trabalhadores de saúde a não se comprometerem e não considerarem o trabalho na ESF como atividade principal. Ricaldoni e Sena (2006) salientam em seu estudo que é essencial haver pessoas comprometidas, criativas e envolvidas com a EPS, para se construírem práticas inovadoras.

Para os facilitadores, a maior dificuldade está em pôr em prática os conceitos adquiridos no curso e "repassar" esses conceitos aos demais integrantes da equipe, de modo que eles também se sintam estimulados a implementar a EPS.

$O$ ato de repassar, transmitir o conhecimento é algo ainda presente no discurso dos sujeitos. De acordo com Freire (2002), o conhecimento não é algo que possa ser transmitido, mas é construído e reconstruído historicamente. O repasse do conhecimento, como se fosse um objeto, não propicia a interação entre o sujeito e aquilo que precisa ser aprendido (Vasconcellos, 1992).

Essa forma de educar é denominada por Freire (2006b) de educação "bancária", em que os conhecimentos são depositados nos educandos pelo professor que se julga possuidor do saber. Dessa forma, o educador se assume enquanto sujeito do processo, e os educandos são meros objetos. Ao contrário dessa concepção, Freire (2006b) destaca que, no processo de ensino, tanto o educador quanto o educando são educados, ambos são sujeitos do processo, pois constroem o conhecimento em comunhão uns com os outros.

Anastasiou (2007) relata que o processo de ensino envolve o apreender e o aprender. O apreender significa segurar, prender, pegar, tomar para si, implica uma ação. Por outro lado, o verbo aprender significa tomar conhecimento, não pressupõe uma ação. Como o aprender é algo mais presente na formação dos sujeitos, pela influência da pedagogia tradicional, a dificuldade relatada pelos participantes sobre a falta de motivação da equipe pode estar associada à forma passiva de os facilitadores compartilharem seus conhecimentos.

Freire (2002) e Vasconcellos (2007) mencionam que a motivação surge, sobretudo, da identificação do objeto de conhecimento com a realidade dos sujeitos. Pois os sujeitos não substituem e nem somam seus conhecimentos, mas os constroem com base em seus conhecimentos prévios; dessa forma, só haverá incorporação de novos conceitos quando houver a participação ativa no processo de reconstrução, e quando os novos conhecimentos fizerem parte da realidade e corresponderem às necessidades dos sujeitos (Roschke, 2006). O exercício de aproximar o objeto de ensino à realidade do trabalho deve ser uma constante na atuação dos tutores e facilitadores.

O estudo de Job (2006) também revela que as atitudes dos facilitadores se restringem a transmitir o conhecimento, não envolvendo as pessoas no processo de discussão.

Os entrevistados citam que há muita resistência dos profissionais que não participaram do curso em aceitar as novas propostas de trabalho. De acordo com eles, a atuação do facilitador é mal interpretada pelos demais profissionais:

"Eu queria saber se tem alguma fórmula mágica para gente fazer as pessoas aceitarem [...]". (F5)

“[...] é muito difícil fazer com que as outras pessoas entendam que essa mudança tem que acontecer e que essas pessoas também vejam que você não está querendo se aparecer". (F7) 
Um tutor refere que essa resistência dos profissionais pode estar relacionada à falta de persistência dos facilitadores, que desistem de implementar a EPS logo que esbarram em alguma dificuldade. Todas essas dificuldades vivenciadas pelos facilitadores podem estar associadas à falta de compreensão do papel do facilitador, tanto por parte dos profissionais e, até mesmo, dos próprios facilitadores. O estudo de Ricaldoni e Sena (2006), apesar de reconhecer as potencialidades da pedagogia problematizadora utilizada pela EPS, questiona se os profissionais de fato a dominam.

É preciso considerar que assumir o papel de tutor e facilitador em meio a um contexto repleto de obstáculos representa um grande desafio, que não será superado instantaneamente. É no dia a dia, aprendendo com os erros, que tutores, facilitadores e demais profissionais devem construir esse novo jeito de agir em saúde.

\section{Necessidades sentidas por tutores e facilitadores de EPS}

Os discursos revelam diversas necessidades vivenciadas por tutores e facilitadores para implementar a EPS. Entre as relacionadas ao profissional, destacou-se a necessidade de apoio da equipe, atitudes de respeito e valorização do profissional.

O apoio da equipe, conforme os entrevistados, torna-se essencial para a implementação da EPS, uma vez que esta exige uma construção coletiva. No entanto, eles revelam que há muita resistência dos profissionais em relação à proposta da EPS. Este mesmo resultado foi encontrado no estudo de Job (2006), também realizado com facilitadores.

Para Peduzzi (2007), o trabalho em equipe pode ser reconhecido a partir da identificação de um conjunto de elementos. Entre esses elementos a autora cita a colaboração e a cooperação entre os profissionais, o que contraria a fala a seguir, em que um dos profissionais expressa o grau de descrédito à proposta da EPS:

"[...] no primeiro dia que eu cheguei após o curso, uma pessoa, um profissional me perguntou: O que vocês ficaram fazendo lá? Daí eu falei um pouco da filosofia, da reflexão no processo de trabalho [...] E essa pessoa me disse assim: quantas maconhas você fumou hoje?". (F4)

O apoio da equipe é importante, pois a aprendizagem na EPS se dá, sobretudo, no coletivo. Os diferentes olhares e concepções permitem maior aproximação da realidade, à medida que se detectam pontos cegos e se levantam distintas questões, possibilitando a produção das insatisfações, as quais são essenciais para desencadear mudanças (Feuerwerker, 2005).

Cabe salientar que, ao valorizar o trabalho coletivo, a EPS não exclui a singularidade do sujeito. Pois, conforme Morin (2006), o sujeito oscila entre o princípio da exclusão e o princípio da inclusão. O princípio da exclusão representa a singularidade do sujeito, isto é, não há ninguém no mundo que pensa e age da mesma forma que outra pessoa. Já o princípio da inclusão é, ao mesmo tempo, complementar e oposto ao descrito anteriormente. Neste o sujeito compartilha ou adota ideais de outra pessoa, ou seja, o sujeito inclui, na sua subjetividade, outro sujeito, criando a oportunidade de comunicação.

Os tutores também reconhecem, como necessidade, a importância de se respeitar e ter consciência da limitação do Homem durante o processo de implementação da EPS. A limitação humana existe devido ao contínuo processo de produção do sujeito (Freire, 2006a; Campos, 2000). O inacabamento justifica a constante busca do Homem por algo mais. Essa busca, para Freire (2006a), expressa o fundamento da educação enquanto um processo permanente.

Freire (2006a) acrescenta que o Homem, ao perceber-se inacabado, tem consciência de que sua existência no mundo não está isenta de influências sociais, econômicas, culturais, ideológicas e políticas, e nem é totalmente escrava delas. Nesse sentido, o profissional de saúde deve estar consciente de que a ideologia dominante pode ser alterada pela inserção de novas práticas, as quais devem ser permanentemente apreendidas. 
Outra necessidade relatada pelos facilitadores refere-se à valorização do profissional de saúde pela gestão, pelos próprios profissionais e pela população.

"[...] quando eu falo valorizado, eu falo tanto valorizado pelo trabalho que ele desempenha, a maneira como ele desempenha o trabalho, quanto pela valorização profissional em termos de ganho mesmo".

Um tutor, por sua vez, declara que é preciso que os próprios profissionais comecem a se valorizar, utilizando os avanços percebidos, no dia a dia, na prática do trabalho.

"[...] então quem vê hoje a saúde da família, sabe que mudou muito, mas as pessoas que estão lá no dia-a-dia elas percebem que a demanda aumentou, que o trabalho delas aumentou e que talvez a qualidade do que elas fazem não é percebido. Então quando vai qualificar isso, é realmente mostrar o quanto que avançou, o quanto que é importante o trabalho que elas fazem". (T2)

Para que o profissional sinta-se valorizado, Campos (1997) refere que é preciso, entre outras coisas, que o trabalho seja reconhecido pelo próprio trabalhador, pelo cliente e pela sociedade. Contudo, esse reconhecimento não acontece, pois a forma como a assistência à saúde está organizada, isto é, fragmentada, traz prejuízos tanto para o trabalhador quanto para a sociedade. A fixação do profissional em uma determinada atividade produz, no mesmo, alienação; ele perde a capacidade de criar, como também não se sente ativo no processo e, portanto, não responsável pelo objetivo final da intervenção, que é a produção de saúde. O mesmo autor acrescenta que, ao se concentrar em atos esvaziados de sentido, não há vocação que resista à repetição de ações parcelares.

Para transformar esse cenário, Campos (1997) aponta alguns caminhos. Corroborando os resultados deste estudo, uma dessas estratégias seria a aproximação dos trabalhadores com os resultados de seus trabalhos. Para conseguir atingir essa aproximação, é importante favorecer e criar mecanismos que estimulem a participação e o envolvimento de todos os profissionais da equipe. Além disso, garantir a liberdade aos profissionais, mas também delegar a eles responsabilidades. A combinação de autonomia profissional com definições de responsabilidades representa uma das principais estratégias para se assegurar a qualidade em saúde; no entanto, o equilíbrio entre essas duas condições não figura o ponto ideal de funcionamento. É necessário descobrir diversas combinações de graus de autonomia e responsabilidades, considerando cada contexto.

Também emergiram necessidades relacionadas ao processo de trabalho. De acordo com os participantes, é preciso criar espaços de discussão.

"[...] a gente tem que ter um momento de maior proximidade mesmo, de discussão".

"[...] criar espaços de discussões, espaços horizontais de discussões [...] promover espaço de discussão, dentro da unidade, dentro da equipe, no espaço com o usuário, com controle social, conselho municipal, com a academia". (T1)

Para os sujeitos do estudo, os espaços de discussão favorecem a construção coletiva e facilitam o enfrentamento dos problemas. Discutir o processo de trabalho implica assumir responsabilidades, e isso gera desconfortos, uma vez que vêm à tona necessidades que exigem uma ação. Um estudo realizado com docentes de uma universidade estadual do Paraná revelou que os espaços de discussão promovidos pelas ações de educação permanente contribuem, positivamente, para o profissional refletir sobre sua prática pedagógica (Faria, 2008).

Campos (2000) fala sobre a importância da existência de espaços coletivos. Para este autor, um espaço coletivo é um lugar e um tempo específico, em que se dá o encontro entre sujeitos. Estes espaços são destinados à comunicação, escuta, expressão de desejos, interesses, aspectos da realidade e, também, à análise e elaboração de estratégias que se destinam à solução de necessidades. 
Os espaços coletivos são importantes, pois favorecem o desenvolvimento integral das pessoas, utilizando o próprio trabalho e as atividades cotidianas. Com isso, superam-se iniciativas episódicas que não promovem alterações nas organizações (Campos, 2000). Dessa forma, é preciso que os espaços coletivos se incorporem ao cotidiano dos trabalhadores de saúde, sejam em assembleias com profissionais e usuários, em reuniões ocasionais, em sessões para discussão de casos, oficinas de planejamento, entre outros.

Os discursos apresentam necessidades de materiais e espaço físico para a realização de reuniões e atividades programadas.

"[...] quando você começa a discutir o seu processo de trabalho, as dificuldades, as facilidades, identifica os problemas e quando você vai fazer uma proposta de intervenção para resolver o problema [...] Você precisa de estrutura".

Necessidades semelhantes foram encontradas no estudo de Cotta et al (2006). Nesse estudo, a falta de transporte, de infraestrutura e de equipamentos foram as principais dificuldades vivenciadas por profissionais da Equipe Saúde Família (ESF).

Os facilitadores afirmam que, muitas vezes, a equipe não consegue enxergar as próprias necessidades por estar "naturalizada" com os problemas presentes na localidade. Quando isso acontece, é muito importante contar com o olhar de quem está fora do processo. Esse auxílio é citado como uma necessidade, pelos participantes do estudo.

Quando uma prática social se estabiliza, se repete com certa frequência, ela é percebida como se fosse uma regra natural; dessa forma, os sujeitos sentem dificuldades em mudar e, até mesmo, perceber falhas em uma prática que parece ser tão natural (Brasil, 2005b). Contar com o apoio de uma pessoa que esteja de fora do processo para perceber as falhas é algo importante; no entanto, isso não deve eximir a equipe de refletir sobre o processo de trabalho. Campos (2000) discute isso ao se referir aos Apoiadores Institucionais, cuja tarefa principal é promover, acompanhar e apoiar processos de mudança nos modelos de atenção e nos modos de gestão em saúde, tomados como indissociáveis.

Os participantes salientam a importância de se formarem novos facilitadores. Para os participantes, a formação de mais facilitadores fortaleceria o processo de implementação da EPS, uma vez que mais pessoas compreenderiam a importância dessa política, amenizando a resistência dos trabalhadores acerca da EPS.

"[...] acho que deveria ter outro processo agora aqui, em Londrina deveria ter um outro processo com os facilitadores para formar mais gente nas mesmas unidades".

Por outro lado, um tutor afirma que a compreensão sobre a política de EPS não deve depender totalmente da formação de facilitadores, mas sim da prática da EPS e de tempo para que essa proposta seja amadurecida e disseminada pelos facilitadores já formados. Testa, citado por Giovanella (1989), refere que, além de novas consciências determinarem novas práticas, novas práticas também determinam novas consciências.

"[...] não adianta você querer fazer mil cursos, formar cinco mil facilitadores, que desses cinco mil vão ser facilitadores efetivamente no máximo 10 pessoas. Então é questão de tempo. A política já foi gestada, já foi iniciada, mas demora um pouco". (T9)

Não se pode negar: a formação de facilitadores contribui para fortalecer a implementação de EPS; contudo, é preciso ter cautela e não fazer do curso a solução de todos os problemas, pois, assim, correse o risco de reproduzir as práticas hegemônicas, em que se realizavam diversos cursos de capacitação, sem, contudo, promover mudanças. A formação de facilitadores não pode constituir a única estratégia para desenvolver a EPS; o curso traz os meios, mas o que de fato determina a mudança é a implementação da EPS no cotidiano do trabalho; afinal, o foco é o trabalho, e não o curso. 
Conforme afirma Nunes et al. (2008), a Educação Permanente em Saúde é um processo, e não uma capacitação estanque, portanto, a formação de facilitadores não deve se encerrar como mais um curso para profissionais.

A maior necessidade apontada pelos participantes refere-se ao apoio da gestão, isto é, à institucionalização da política EPS. Os participantes afirmam que, para a EPS ser assumida como uma estratégia de mudança, é preciso que ela seja institucionalizada, pois é preciso garantir um espaço institucional para assegurar a sustentabilidade dessa política.

“[...] a educação permanente sozinha não vai fazer milagre, precisa que a instituição crie outros instrumentos que colaborem na mesma direção, nós ficamos remando contra a maré sozinhos". (T7)

Essa também é uma necessidade apontada pelo estudo de Limo et al. (2009), realizado com coordenadores ou responsáveis pelo setor de educação permanente dos serviços públicos de saúde do município de Florianópolis. Segundo esses sujeitos, há falta de estímulo por parte da Secretaria Municipal de Saúde, que, muitas vezes, apenas encaminha capacitações obrigatórias e padronizadas nacionalmente pela gestão tripartite.

Vale ressaltar que a percepção de falta de apoio da gestão municipal pode apontar para a incompreensão da gestão sobre a magnitude desse processo. Como afirma Farah (2006), o processo de EPS não se limita a processos de capacitação; é fundamental que a gestão assuma sua responsabilidade de acompanhar e supervisionar as equipes no processo de trabalho.

Os tutores citam que um dos caminhos para institucionalizar a EPS é avaliar e apresentar os resultados, os reflexos desse processo sobre a prática e os indicadores de saúde. As ações de monitoramento e avaliação devem ser incorporadas ao serviço como uma atividade permanente (Roschke, 2006).

Corroborando a ideia do tutor sobre avaliar as ações de EPS, a nova Portaria 1996/GM menciona que a Secretaria de Gestão do Trabalho e da Educação na Saúde propõe indicadores para o acompanhamento da política de EPS dentro do processo de pactuação unificada de indicadores, que serão integrados aos indicadores do Pacto pela Saúde (Brasil, 2007).

\section{Considerações finais}

A educação permanente em saúde, enquanto uma proposta contra-hegemônica, traz necessidades e dificuldades para os profissionais de saúde que buscam implementá-la no dia-a-dia do trabalho, sobretudo, para tutores e facilitadores de EPS.

Os resultados desse estudo evidenciaram uma série de necessidades, entre elas destacam-se: o apoio da equipe, a criação de espaços de discussão, a valorização do profissional e, sobretudo, o apoio da gestão no processo de implementação da EPS. Em relação às dificuldades, os sujeitos salientaram a resistência dos profissionais e da própria organização da assistência pautada na lógica biomédica. Também houve relatos sobre a falta de compromisso de alguns profissionais e limitação de governabilidade.

Com base nesses resultados, percebe-se que tutores e facilitadores, sobretudo tutores, em certos momentos, demonstram maturidade em relação à EPS, sobretudo quando remetem a esta política a necessidade de construção processual e que envolve o coletivo. Por outro lado, em outras situações, trazem discursos relacionados à transmissão de saberes, a valorização demasiada de cursos, enfim, características típicas do modelo hegemônico.

Isso revela que tutores e facilitadores, mesmo tendo passado por um processo de formação e serem considerados profissionais preparados para impulsionar esta política no cotidiano dos serviços de saúde, também estão em processo de evolução, de apropriação desta proposta. Diante disso, é preciso fortalecer a ideia de que a EPS se apreende na prática, com o apoio da gestão e no enfrentamento dos problemas diários dos serviços de saúde. 


\section{Colaboradores}

A autora Fernanda de Freitas Mendonça responsabilizou-se pela coleta e análise dos dados e pela redação do artigo. A autora Elisabete de Fátima Polo de Almeida Nunes responsabilizou-se pela análise dos dados e redação do artigo.

\section{Referências}

ANASTASIOU, L.C. Ensinar, aprender, apreender e processos de ensinagem. In: ANASTASIOU, L.C.; ALVES, L.P. (Orgs.). Processos de ensinagem na universidade: pressupostos para as estratégias de trabalho em aula. 7.ed. Joinville: Univille, 2007. p.15-43.

BRASIL. Ministério da Saúde. Gabinete do Ministro. Portaria no 1996/GM/MS, de 20 de agosto de 2007. Dispõe sobre as diretrizes para a implementação da Política Nacional de Educação Permanente em Saúde e dá outras providências. Brasília: Ministério da Saúde, 2007.

Ministério da Saúde. Secretaria de Gestão do Trabalho e da Educação na Saúde. Departamento de Gestão da Educação na Saúde. A educação permanente entra na roda. Brasília: Ministério da Saúde, $2005 a$.

Ministério da Saúde. Secretaria de Gestão do trabalho e da Educação na Saúde. Departamento de $\overline{G e s t a ̃ o ~ d a ~ E d u c a c ̧ a ̃ o ~ n a ~ S a u ́ d e . ~ C u r s o ~ d e ~ f a c i l i t a d o r e s ~ d e ~ e d u c a c ̧ a ̃ o ~ p e r m a n e n t e ~ e m ~ s a u ́ d e: ~ u n i d a d e ~ d e ~}$ aprendizagem - análise do contexto da gestão e das práticas de saúde. Brasília: Ministério da Saúde, 2005b.

Ministério da Saúde. Gabinete do Ministro. Portaria no 198/GM/MS, de 13 de fevereiro de 2004. Institui a Política Nacional de Educação Permanente em Saúde como estratégia do Sistema Único de Saúde para formação e do desenvolvimento de trabalhadores para o setor e dá outras providências. Brasília: Ministério da Saúde, 2004.

Ministério da Saúde. Conselho Nacional de Saúde. Resolução no 196/96, de 10 de outubro de 1996. Aprova as diretrizes e normas regulamentadoras de pesquisas envolvendo seres humanos. Brasília: Ministério da Saúde, 1996.

CAMPOS, G.W.S. Subjetividade e administração de pessoal: considerações sobre modos de gerenciar o trabalho em equipes de saúde. In: MERHY, E.E.; ONOCKO, R. (Orgs.). Agir em saúde: um desafio para o público. São Paulo: Hucitec, 1997. p.229-66.

Um método para análise e co-gestão de coletivos: a constituição do sujeito, a produção de valor de uso e a democracia em instituições: o método da roda. São Paulo: Hucitec, 2000.

Saúde Paidéia. 3.ed. São Paulo: Hucitec, 2007.

COTTA, R.M.M. et al. Organização do trabalho e perfil dos profissionais do Programa Saúde da Família: um desafio na reestruturação da atenção básica em saúde. Epidemiol. Serv. Saude, v.15, n.3, p.7-18, 2006.

FARAH, B.F. Educação permanente no processo de organização em serviços de saúde: as repercussões do curso introdutório para equipes de saúde da família - experiência do município de Juiz de Fora/MG. 2006. Tese (Doutorado em Saúde Coletiva) - Universidade do Estado do Rio de Janeiro, Rio de Janeiro. 2006.

FARIA, M.J.S.S. et al. Os desafios da educação permanente: a experiência do curso de medicina da Universidade Estadual de Londrina. Rev. Bras. Educ. Med., v.32, n.2, p.248-53, 2008.

FEUERWERKWER, L.C.M. Educação permanente em saúde: uma mudança de paradigmas. Olho Mágico, v.12, n.3, p.13-20, 2005

FREIRE, P. Sobre educação popular: entrevista com Paulo Freire. In: TORRES, R.M. (Org.). Educação popular: um encontro com Paulo Freire. 2.ed. São Paulo: Edições Loyola, 2002. p.67-108. 2006a.

Pedagogia da autonomia: saberes necessários à prática educativa. 33.ed. São Paulo: Paz e Terra,

Pedagogia do oprimido. 44.ed. São Paulo: Paz e Terra, 2006b.

GIOVANELLA, L. Ideologia e poder no planejamento estratégico em saúde: uma discussão da abordagem de Mário Testa. 1989. Dissertação (Mestrado em Saúde Pública) - Escola Nacional de Saúde Pública, Rio de Janeiro. 1989 
JOB, G.A. Educação permanente em saúde: um desafio para a mudança de prática do cuidado em saúde. 2006. Trabalho de conclusão de curso (Graduação em Enfermagem) - Universidade do Extremo Sul Catarinense, Criciúma. 2006.

MARTINS, J.; BICUDO, M.A.V. A pesquisa qualitativa em psicologia: fundamentos e recursos básicos. São Paulo: Centauro, 2005.

MENDONÇA, F.F. Formação de facilitadores de educação permanente em saúde: percepções de tutores e facilitadores. 2007. Dissertação (Mestrado em Saúde Coletiva) - Universidade Estadual de Londrina, Londrina. 2007.

MERHY, E.E.; FEUERWEKER, L.C.M.; CECCIM, R.B. Educación permanente en salud una estrategia para intervenir en la micropolítica del trabajo en salud. Salud Colect. v.2, n.2, p.147-60, 2006.

MORIN, E. A cabeça bem-feita: repensar a reforma, reformar o pensamento. 12.ed. Rio de Janeiro: Bertrand Brasil, 2006.

NUNES, M.F. et al. A proposta da educação permanente em saúde na formação de cirurgiões-dentistas em DST/HIV/Aids. Interface - Comunic., Saude, Educ., v.12, n.25, p.413-20, 2008

PEDUZZI, M. Trabalho em equipe de saúde da perspectiva de gerentes de serviços de saúde: possibilidades da prática comunicativa orientada pelas necessidades de saúde dos usuários e da população. 2007. Tese (Livre-docência) - Escola de Enfermagem da Universidade de São Paulo, São Paulo. 2007.

RIBEIRO, E.M.; PIRES, D.; BLANK, V.L.G. A teorização sobre processo de trabalho em saúde como instrumental para análise do trabalho no Programa Saúde da Família. Cad Saude Publica, v.20, n.2, p.438-46, 2004.

RICALDONI, C.A.C.; SENA, R.R. Educação permanente: uma ferramenta para pensar e agir no trabalho em enfermagem. Rev. Lat.-am. Enferm., v.14, n.6, p.837-42, 2006.

ROSCHKE, M.A.C. Educação permanente - compreensão: alguns conceitos e características essenciais. Olho Mágico, v.13, n.3, p.32-5, 2006.

THIOLLENT, M. Concepção e organização da pesquisa. In: da pesquisa-ação. 13.ed. São Paulo: Cortez, 2004. p.47-72.

(Org.). Metodologia

TRIVIÑOS, A.N.S. Pesquisa qualitativa. In: (Org.). Introdução à pesquisa em ciências sociais: a pesquisa qualitativa em educação. São Paulo: Atlas, 1987. p.116-75.

TURATO, E.R. Métodos qualitativos e quantitativos na área de saúde: definições, diferenças e seus objetos de pesquisa. Rev. Saude Publica, v.39, n.3, p.507-14, 2005.

VASCONCELLOS, C. Metodologia dialética em sala de aula. Rev. AEC, v.21, n.83, p.28-55, 1992. 
MENDONÇA, F.F; NUNES, E.F.P.A. Necesidades y dificultades de facilitadores y tutores para desarrollar la política de educación permanente en salud en un gran município en Paraná, Brasil. Interface - Comunic., Saude, Educ., v.15, n.38, p.871-82, jul./set. 2011.

Para fortalecer la política de Educación Permanente en Salud (EPS) se formaron los tutores y facilitadores de la educación permanente en salud. El objetivo de ese estudio es fue descubrir sus necesidades y dificultades durante el proceso de aplicación de la EPS. Se trata de una investigación cualitativa con nueve tutores y dez facilitadores de EPS en Londrina, estado de Paraná. Como herramienta de recopilación de datos se llevaron a cabo entrevistas semi-estructuradas y los datos fueron analizados como el análisis del discurso propuesto por Martins y Bicudo. Entre as necesidades se destaca la institucionalización de la EPS y entre las dificultades, la persistencia de la práctica hegemónica. Es necesario consolidar la EPS a través de su práctica en los servicios de salud, sólo de esta manera, los tutores, facilitadores y otros profesionales de la salud tendrán la capacidad de superar las limitaciones actuales del proceso de aplicación de la EPS.

Palabras clave: Políticas de salud. Educación Permanente en Salud. Proceso de trabajo en Salud. Administración de Personal en Salud. 